\title{
A Nonlinear Strength Criterion for Frozen Sulfate Saline Silty Clay with Different Salt Contents
}

\author{
Yanhu Zhao, ${ }^{1,2}$ Yuanming Lai $\mathbb{C}^{1,2}$ Jing Zhang, ${ }^{1,2}$ and Chong Wang ${ }^{3}$ \\ ${ }^{1}$ State Key Laboratory of Frozen Soil Engineering, Northwest Institute of Eco-Environment and Resources, \\ Chinese Academy of Sciences, Lanzhou 730000, China \\ ${ }^{2}$ University of Chinese Academy of Sciences, Beijing 100049, China \\ ${ }^{3}$ Key Laboratory of Mechanics on Disaster and Environment in Western China, \\ The Ministry of Education of China and School of Civil Engineering and Mechanics, Lanzhou University, \\ Lanzhou 730000, China \\ Correspondence should be addressed to Yuanming Lai; ymlai@lzb.ac.cn
}

Received 21 August 2018; Accepted 5 November 2018; Published 2 December 2018

Academic Editor: Jun Liu

Copyright (C) 2018 Yanhu Zhao et al. This is an open access article distributed under the Creative Commons Attribution License, which permits unrestricted use, distribution, and reproduction in any medium, provided the original work is properly cited.

It has been proven that the mechanical properties of frozen saline soils are different from frozen soils and unfrozen saline soils. In this paper, in order to study the effects of the salt contents on the strength characteristics of frozen soils, a series of conventional triaxial compression tests are carried out for frozen saline silty clay with $\mathrm{Na}_{2} \mathrm{SO}_{4}$ contents $0.0,0.5,1.5$, and $2.5 \%$ under confining pressures from $0 \mathrm{MPa}$ to $18 \mathrm{MPa}$ at $-6^{\circ} \mathrm{C}$, respectively. The experimental results show that the strength of frozen saline silty clay presents obvious nonlinearity, the strength of frozen saline silty clay increases with increasing confining pressures at first, but with a further increase in confining pressures, the strength decreases because of pressure melting and crushing phenomena under high confining pressures, and salt contents have an important influence on strength of frozen saline silty clay. A strength criterion is proposed on the basis of the experimental results. The strength criterion could well reflect the nonlinear strength characteristic of frozen saline silty clay and the influence of salt contents on frozen saline silty clay.

\section{Introduction}

The essential difference between frozen saline soils and unfrozen soils is the ice and salt existing in frozen saline soils, which has an important influence on cohesive strength of the soil particles. The effect of salt content on the mechanical properties of frozen saline silty clay is considerable. Research results suggest that sulfate soil is widely distributed in the western China [1]. With the implementation of the Belt and Road Initiative, infrastructure constructions in the western China, such as metro engineering, tunnel construction, bridges, and other engineering activities, will be of top priority. The strength of frozen soils has great design guidance for construction in the western China. So far, research on strength characteristics of frozen saline silty clay is rarely reported. The strength characteristics of frozen saline soils are urgently needed.

The Mohr-Coulomb strength criterion, which has linear strength envelopes, is one of the widely used strength criteria nowadays. However, a majority of experimental results show that the strength envelope for most of the geomaterials is nonlinear. The linear Mohr-Coulomb strength criterion is not suitable for most of the geomaterials, such as frozen soils and sand. Using the nonlinear strength criterion to reflect strength characteristics of most of the geomaterials is more reasonable. There are some nonlinear strength criteria for geomaterials. So far, for sandy soils, there are two popular strength criteria, MN strength criterion [2] and LD strength criterion [3], respectively. Later, many researchers $[4,5]$ proposed new strength criteria on the basis of them. Yao et al. [6] proposed a unified hardening (UH) model for overconsolidated clays based on the MN criterion and the corresponding transforming stress method. Frozen soils are made up of mineral particles, ice inclusions, liquid water, and gaseous inclusions [7]. Compared with unfrozen soils, the strength and deformation characteristics of frozen soils are more complex owing to the existence of ice, so these 
strength criteria are unreasonable for frozen soils. A series of studies [8-23] on the strength and deformation characteristics of frozen soils were carried out. The experimental results showed that the strength of frozen soils increases with increasing confining pressures at first, but with a further increase in confining pressures, the strength decreases for pressure melting and crushing phenomena under high confining pressures $[21,24,25]$. And many strength criteria were presented for frozen soils. Fish [26] and Ma et al. [27] presented parabolic yield criteria for frozen soils, respectively. Lai et al. [21] presented a nonlinear Mohr criterion which can describe the pressure melting and crushing phenomena of frozen soils. Yang et al. $[28,29]$ established a new strength criterion for frozen soils based on MN and LD criteria, and then, Yang et al. [30] presented a better one based on the Hoek-Brown criterion.

Compared with general frozen soils, the strength criterion of frozen saline silty clay is more complex than that of general frozen soils for the existence of salt crystals. Liao et al. [31] found that the existence of salt lowers the freezing temperature and salt content can influence the strength of frozen soils. It was proven that the content of sodium sulfate has an important influence on the mechanical properties of frozen soils [32], so strength criteria for general frozen soils and unfrozen soils are not available for frozen saline silty clay. Liao et al. [31] established a strength criterion for frozen sodium sulfate saline soils, which can reflect the influence of salt content on strength. The studies mentioned above are the latest developments in strength criterion and represent a great advance in the investigation on this domain.

In this paper, a series of conventional triaxial compression tests were carried out for frozen saline silty clay with $\mathrm{Na}_{2} \mathrm{SO}_{4}$ contents $0.0,0.5,1.5$, and $2.5 \%$ under confining pressure from $0 \mathrm{MPa}$ to $18 \mathrm{MPa}$ at $-6^{\circ} \mathrm{C}$, respectively. Based on the experimental results, a new strength criterion was proposed to describe strength characteristics of frozen saline silty clay, which can well reflect the nonlinear strength characteristic of frozen saline silty clay and the influence of salt content on strength.

\section{Test Conditions and Results}

2.1. Description of the Test and Test Conditions. The soil studied was taken from Qinghai-Tibet plateau, and its grain size composition is given in Table 1 . The soil studied contains lots of salinity, so we must desalinate the soil firstly. In order to desalinate the soil, salt in saline silty clay was removed with distilled water until the total amount of soluble salts is approximately zero. An electronic conductivity pen was used to measure the electronic conductivity of the soil during desalinating. When the electronic conductivity is close to 0 , it is considered that the total amount of soluble salts is approximately zero. Secondly, the desalinated soil sample was dried at $105^{\circ} \mathrm{C}$ for $24 \mathrm{~h}$ and then pulverized and filtered with a $2 \mathrm{~mm}$ sieve. Finally, the sieved soils were selected to make up the sodium sulfate saline silty clay samples whose salt contents were $0.0,0.5,1.5$ and $2.5 \%$, respectively. The process of making samples is as follows: (1)
TABLE 1: Grain size composition of saline silty clay (unit: \%).

\begin{tabular}{lcccc}
\hline$>0.50 \mathrm{~mm}$ & $\begin{array}{c}0.50- \\
0.25 \mathrm{~mm}\end{array}$ & $\begin{array}{c}0.25- \\
0.075 \mathrm{~mm}\end{array}$ & $\begin{array}{c}0.075- \\
0.005 \mathrm{~mm}\end{array}$ & $<0.005 \mathrm{~mm}$ \\
\hline 0.10 & 0.53 & 7.8 & 70.34 & 21.23 \\
\hline
\end{tabular}

mix the soil with the salt; (2) mix the mixture of soil and salt with water; (3) samples were made by testing mold. The experimental apparatus is the MTS-810 material testing system. The cylindrical soil samples with $61.8 \mathrm{~mm}$ in diameter and $125 \mathrm{~mm}$ in height were prepared. The test procedure was as follows: (1) the soil samples were saturated with the vacuum method so that the saturated water content of the soil sample is approximately 22\%; (2) the soil samples were frozen at $-6^{\circ} \mathrm{C}$ for $24 \mathrm{~h}$ using the cooling equipment; (3) the soil samples were put into a pressure cell and were kept for $2 \mathrm{~h}$ at $-6^{\circ} \mathrm{C}$ using the incubator; (4) the soil samples were loaded under the confining pressures of 0-18 MPa; and (5) triaxial stress was applied. The loading rate during the testing process is $1.25 \mathrm{~mm} / \mathrm{min}$ according to [33].

2.2. Test Results. Figure 1 shows the typical stress-strain curves of frozen saline silty clay with $\mathrm{Na}_{2} \mathrm{SO}_{4}$ content $1.5 \%$ under confining pressures from $0 \mathrm{MPa}$ to $18 \mathrm{MPa}$ at $-6^{\circ} \mathrm{C}$, respectively.

From Figure 1, it is found that the confining pressures have a large influence on the deviator stress-axial strain relationship of frozen saline silty clay. The frozen saline silty clay presents strain hardening, and the stress-strain curves have no peak values for $\varepsilon_{\mathrm{a}} \leq 15 \%$, when confining pressures range from $0 \mathrm{MPa}$ to $18 \mathrm{MPa}$ at $-6^{\circ} \mathrm{C}$. The frozen saline silty clay produces volume contraction at first and then produces volume expansion when confining pressure $<5 \mathrm{MPa}$. But with a further increase in confining pressures, the frozen saline silty clay only produces volume contraction. The strength of frozen saline silty clay increases with increasing confining pressures, when confining pressure $<10 \mathrm{MPa}$. The strength of frozen saline silty clay decreases with increasing confining pressure, when confining pressure $>10 \mathrm{MPa}$. According to the research of Lai et al. [22], in this paper, the values of $\sigma_{1}-\sigma_{3}$ at $\varepsilon_{\mathrm{a}}=15 \%$ are taken as the strength of frozen saline silty clay when confining pressures range from $0 \mathrm{MPa}$ to $18 \mathrm{MPa}$. Figure 2 shows the stress-strain curves of frozen saline silty clay with $\mathrm{Na}_{2} \mathrm{SO}_{4}$ contents $0,0.5,1.5$, and $2.5 \%$ under the confining pressure of $8 \mathrm{MPa}$ at $-6^{\circ} \mathrm{C}$, respectively. From Figure 2, it can be seen that the salt contents have an important influence on the strain-strain relationship.

\section{Strength Theory of Frozen Saline Silty Clay}

Generally, the failure condition can be given by the general state of stress:

$$
F\left(\sigma_{i j}, k_{i}\right)=0
$$

where $F$ is the strength function, $\sigma_{i j}$ is the secondrank symmetric stress tensor, and $k_{i}$ is the strength parameter. 


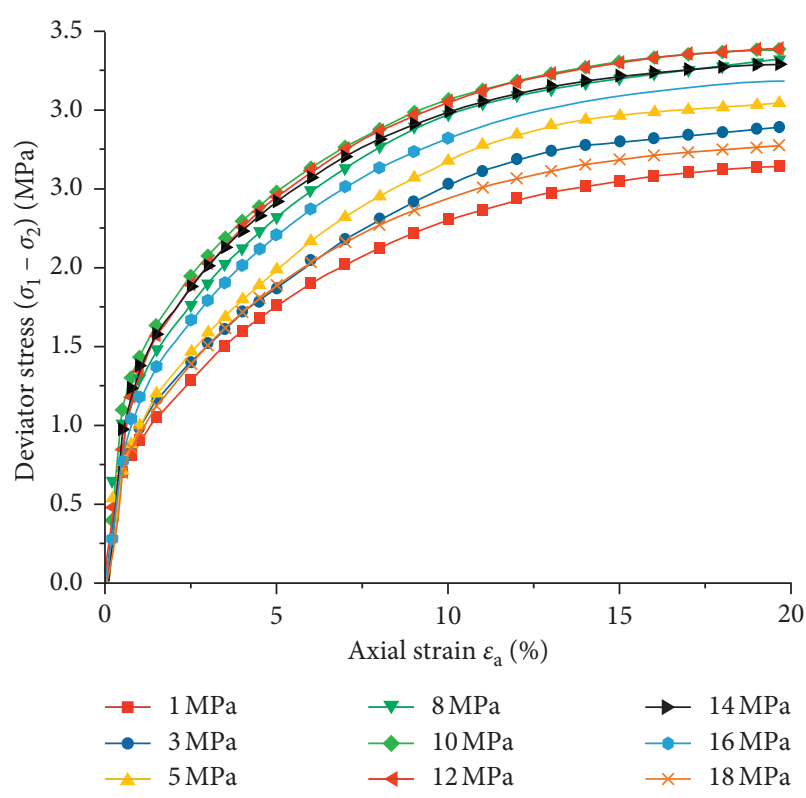

(a)

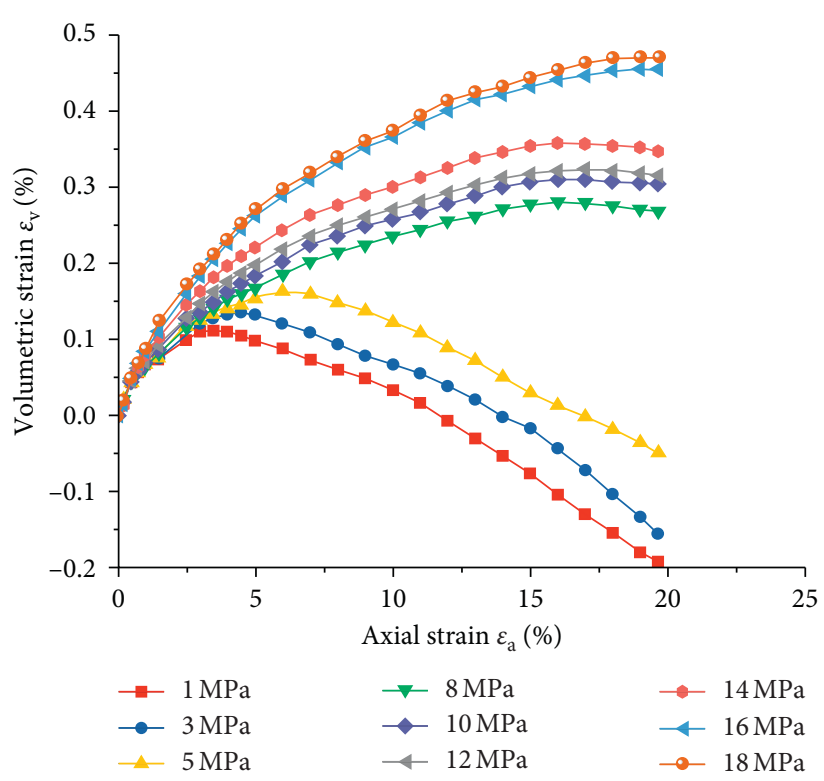

(b)

FIgURE 1: The typical stress-strain curves of frozen saline silty clay with salt content $1.5 \%$.

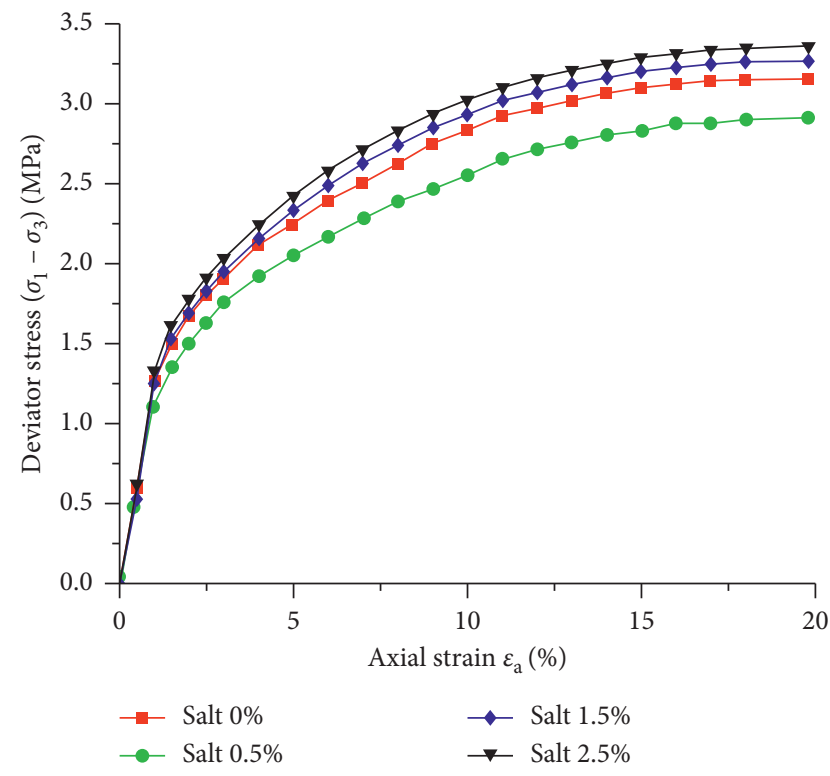

FIGURE 2: The typical stress-strain curves of frozen saline silty clay with different salt contents under a confining pressure of $8 \mathrm{MPa}$.

Equation (1) can also be written by principal stress invariants $I_{1}, I_{2}$, and $I_{3}$ in the principal stress space and $p, q$, and $\theta$ in the $p-q-\theta$ stress space:

$$
\begin{gathered}
F\left(I_{1}, I_{2}, I_{3}, k_{i}\right)=0, \\
F\left(p, q, \theta, k_{i}\right)=0,
\end{gathered}
$$

where $I_{1}, I_{2}$, and $I_{3}$ are the first, second, and third principal stress invariants, respectively. $p$ is the hydrostatic pressure and $q$ is the deviatoric stress. According to the research of Liao et al. [31], Equation (3) can be expressed as

$$
q=f_{p-q} g(\theta),
$$

where $f_{p-q}$ stands for the critical state curve on the $p-q$ plane, $g(\theta)$ represents the shape function on the deviatoric plane, and $\theta$ is Lode's angle.

3.1. Critical Strength Curves of Frozen Saline Silty Clay in $p-q$ Plane. Referring to the research of Chu [34], the critical strength curves of frozen saline silty clay with different salt contents are shown in Figure 3. From Figure 3, the following can be observed. (1) The CSL of frozen saline silty clay with different salt contents passes through the different isotropic tensile points. The reason is that the existence of salt has an important influence on the cohesive strength of frozen soils. (2) The CSL of frozen saline silty clay with different salt contents is nonlinear, and the slope of the CSLs is positive when hydrostatic pressure is relatively small. When hydrostatic pressure reaches a certain value, the CSL is gradually bended downward with the increase of hydrostatic pressure, and the slope of the CSL is negative accordingly. (3) The slope $k$ of the CSL of frozen saline silty clay under different salt contents is different when the hydrostatic pressure $p<8 \mathrm{MPa}$, in detail $k_{0.5}<k_{0}<k_{1.5}<k_{2.5}$. And the relationship between shear strength and hydrostatic pressure can be expressed by

$$
f(p, q)=\frac{a(s)\left(p / p_{\mathrm{a}}\right)^{2}+b(s)\left(p / p_{\mathrm{a}}\right)+c(s)}{\left(p / 9.8687 p_{\mathrm{a}}\right)+d(s)} p_{\mathrm{a}}-q=0,
$$

where $p_{\mathrm{a}}$ is the standard atmospheric pressure, $p_{\mathrm{a}}=$ $0.10133 \mathrm{MPa}$. The parameters $a(s), b(s), c(s)$, and $d(s)$ were gotten by the fitting curves. $a(s), b(s), c(s)$, and $d(s)$ are the material parameters related to salt contents at $-6^{\circ} \mathrm{C}$. 


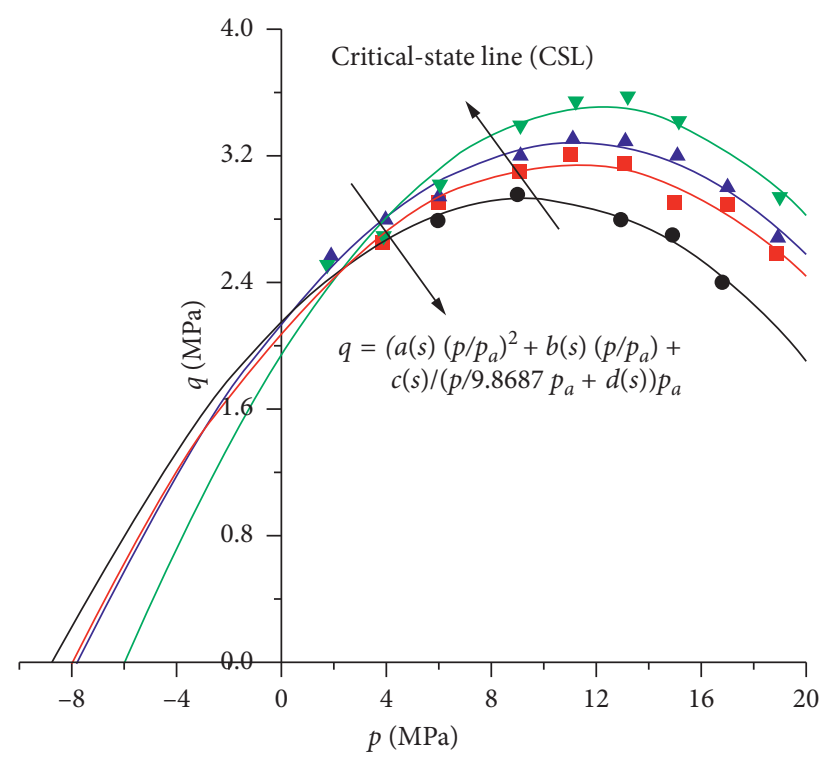

- Salt $0 \%$

- Salt $1.5 \%$

- Salt $0.5 \%$

$\checkmark$ Salt $2.5 \%$

FIgURE 3: Test values and fitting curves of CSL with different salt contents.

$$
\begin{aligned}
a(s)= & -2.815 \times 10^{5} s^{3}+1.07 \times 10^{6} s^{2}-9.754 \times 10^{5} s \\
& -2.009 \times 10^{3} \\
b(s)= & -5.455 \times 10^{5} s^{3}-2.044 \times 10^{6} s^{2}+1.848 \times 10^{6} s \\
& -4.487 \times 10^{3} \\
c(s)= & 6.729 \times 10^{5} s^{3}-2.591 \times 10^{6} s^{2}+2.381 \times 10^{6} s \\
& +4.983 \times 10^{3}, \\
d(s)= & 2.127 \times 10^{5} s^{3}-3.318 \times 10^{5} s^{2}+6.573 \times 10^{4} s \\
& +2.351 \times 10^{4}
\end{aligned}
$$

Based on the Mohr strength theorem, the failure envelope can be written as

$$
F\left(\sigma, \tau, \sigma_{1}, \sigma_{3}\right)=\left(\sigma-\frac{\sigma_{1}+\sigma_{3}}{2}\right)^{2}+\tau^{2}-\left(\frac{\sigma_{1}-\sigma_{3}}{2}\right)^{2}=0
$$

For the conventional triaxial tests, $p=(1 / 3)\left(\sigma_{1}+2 \sigma_{3}\right)$, $q=\sigma_{1}-\sigma_{3}$. Substituting $p, q$ into Equation (7), Equation (7) can be written as

$$
F(p, q)=\left(\sigma-p-\frac{q}{6}\right)^{2}+\tau^{2}-\left(\frac{q}{2}\right)^{2}=0 .
$$

Based on the envelope theory, we can obtain the following formula:

$$
\frac{\partial F}{\partial p} \frac{\partial f}{\partial q}-\frac{\partial F}{\partial q} \frac{\partial f}{\partial p}=0 .
$$

Differentiating Equations (5) and (8), we can get

$$
\begin{aligned}
& \frac{\partial f}{\partial q}=-1 \\
\frac{\partial f}{\partial p}= & \frac{\left[\left(p / 9.8687 p_{\mathrm{a}}\right)+d(s)\right]\left[a(s)\left(p /\left(p_{\mathrm{a}}\right)^{2}\right)+b(s)\left(1 / p_{\mathrm{a}}\right)\right]-\left(1 / 9.8687 p_{\mathrm{a}}\right)\left[a(s)\left(p / p_{\mathrm{a}}\right)^{2}+b(s)\left(p / p_{\mathrm{a}}\right)+c(s)\right]}{\left[\left(p / 9.8687 p_{\mathrm{a}}\right)+d(s)\right]^{2}} p_{\mathrm{a}} \\
& \frac{\partial F}{\partial q}=-\frac{1}{3}\left(\sigma-p-\frac{q}{6}\right)-\frac{q}{2} \\
& \frac{\partial F}{\partial p}=-2\left(\sigma-p-\frac{q}{6}\right) .
\end{aligned}
$$

By substituting Equations (10), (11), (12), and (13) into Equation (9), we can get the following relationship 


$$
\sigma=\frac{[(1 / 3)(p+(q / 6))-(q / 2)]\left\{\left[\left[\left(p / 9.8687 p_{\mathrm{a}}\right)+d(s)\right]\left[a(s)\left(p /\left(p_{\mathrm{a}}\right)^{2}\right)+b(s)\left(1 / p_{\mathrm{a}}\right)\right]-\left(1 / 9.8687 p_{\mathrm{a}}\right)\left[a(s)\left(p / p_{\mathrm{a}}\right)^{2}+b(s)\left(p / p_{\mathrm{a}}\right)+c(s)\right]\right] /\left[\left[\left(p /\left(9.8687 p_{\mathrm{a}}\right)\right)+d(s)\right]^{2}\right] p_{\mathrm{a}}\right\}+2(p+(q / 6))}{2+(1 / 3)\left\{\left[\left[\left(p / 9.8687 p_{\mathrm{a}}\right)+d(s)\right]\left[a(s)\left(p /\left(p_{\mathrm{a}}\right)^{2}\right)+b(s)\left(1 / p_{\mathrm{a}}\right)\right]-\left(1 / 9.8687 p_{\mathrm{a}}\right)\left[a(s)\left(p / p_{\mathrm{a}}\right)^{2}+b(s)\left(p / p_{\mathrm{a}}\right)+c(s)\right]\right] /\left[\left[\left(p /\left(9.8687 p_{\mathrm{a}}\right)\right)+d(s)\right]^{2}\right] p_{\mathrm{a}}\right\}}
$$

By substituting Equation (14) into Equation (8), we can get the shear tress $\tau$ as follows:

$$
\tau=\sqrt{\left(\frac{q}{2}\right)^{2}-\left\{\frac{[(1 / 3)(p+(q / 6))-(q / 2)]\left\{\left[\left[\left(p / 9.8687 p_{\mathrm{a}}\right)+d(s)\right]\left[a(s)\left(p /\left(p_{\mathrm{a}}\right)^{2}\right)+b(s)\left(1 / p_{\mathrm{a}}\right)\right]-\left(1 / 9.8687 p_{\mathrm{a}}\right)\left[a(s)\left(p / p_{\mathrm{a}}\right)^{2}+b(s)\left(p / p_{\mathrm{a}}\right)+c(s)\right]\right] /\left[\left[\left(p / 9.8687 p_{\mathrm{a}}\right)+d(s)\right]^{2}\right] p_{\mathrm{a}}\right\}+2(p+(q / 6))}{\left.2+(1 / 3)\left\{\left[\left(p / 9.8687 p_{\mathrm{a}}\right)+d(s)\right]\left[\left[a(s)\left(p /\left(p_{\mathrm{a}}\right)^{2}\right)+b(s)\left(1 / p_{\mathrm{a}}\right)\right]-\left(1 / 9.8687 p_{\mathrm{a}}\right)\left[a(s)\left(p / p_{\mathrm{a}}\right)^{2}+b(s)\left(p / p_{\mathrm{a}}\right)+c(s)\right]\right] /\left[\left(p / 9.8687 p_{\mathrm{a}}\right)+d(s)\right]^{2}\right] p_{\mathrm{a}}\right\}}-\frac{q}{6}\right\}^{2}} .
$$

The friction angle $\varphi$ of frozen saline silty clay can be calculated by

$$
\begin{aligned}
\varphi & =\arctan \left(\frac{d \tau}{d \sigma}\right)=\arctan \left(-\frac{\partial f / \partial \sigma}{\partial f / \partial \tau}\right) \\
& =\arctan \left(-\frac{\sigma-p-(q / 6)}{\tau}\right) .
\end{aligned}
$$

From Equations (14), (15), and (16), it can be seen that the friction angle $\varphi$ of frozen saline silty clay is related to salt content. Using Equations (14), (15), and (16), we can get the curves between friction angle $\varphi$ and hydrostatic pressure with different salt contents $0.0,0.5,1.5$, and 2.5\%, shown in Figure 4.

From Figure 4, the following can be observed. (1) Under any same hydrostatic pressure, the friction angles reached a minimum value when salt content is equal to $0.5 \%$. (2) Under each kind of salt content, the friction angles decrease with the increase of hydrostatic pressure. (3) Salt content has an important influence on the friction angles when the hydrostatic pressure $p<18 \mathrm{MPa}$. The influence of salt content on the friction angles is less obvious when $p>18 \mathrm{MPa}$. This phenomenon is contrary to the finding of Liao et al. [31]. (4) Under any salt content, when the hydrostatic pressure $p$ is beyond a certain value, the friction angles obtained by Equation (16) will become negative. The main reason to result in this phenomenon is the pressure melting phenomenon under high confining pressures. The greater the confining pressure, the more obvious the phenomenon so that its strength is gradually reduced, and the strength envelope bends downwards gradually, so the calculated friction angles is negative.

Using Equations (14) and (15), we can get the shear strength envelope of frozen saline silty clay in the $\sigma-\tau$ space, shown in Figure 5. From Figure 5, it can be seen that the strength envelope is able to reflect the strength of frozen saline silty clay considering the influence of confining pressures well.

3.2. Strength Formulation in $\pi$ Plane. The experiments show that failure curves of some geomaterials in $\pi$ plane are close to the SMP criterion [35], so we take the shape function of the SMP criterion in $\pi$ plane as the shape function of frozen saline silty clay in the $\pi$ plane. Matsuoka et al. [36] gave the shape function for the SMP criterion in $\pi$ plane as follows:

$$
\begin{aligned}
& g(\theta)=\frac{\sqrt{3}\left(\sqrt{8+\sin ^{2} \varphi_{0}}-\sin \varphi_{0}\right)}{4 \sqrt{2+\sin ^{2} \varphi_{0}} \cos \vartheta}, \\
& \vartheta=\frac{1}{3} \cos ^{-1}\left[-\left(\frac{3}{2+\sin ^{2} \varphi_{0}}\right)^{3 / 2} \sin \varphi_{0} \cos 3 \theta\right] \\
& \left(0^{\circ} \leq \theta \leq 60^{\circ}\right) \text {, }
\end{aligned}
$$

$$
\tan \varphi_{0}=\frac{2 \sqrt{2}}{3} \tan \varphi
$$

where $\varphi_{0}$ is the friction angle in the SMP.

In this paper, the shape function for frozen saline silty clay in $\pi$ plane can be written as

$$
g(\theta)=\frac{\sqrt{3}\left(\sqrt{8+\sin ^{2} \varphi_{0}}-\sin \varphi_{0}\right)}{4 \sqrt{2+\sin ^{2} \varphi_{0}} \cos \left\{(1 / 3) \cos ^{-1}\left[-\left(3 /\left(2+\sin ^{2} \varphi_{0}\right)\right)^{3 / 2} \sin \varphi_{0} \cos 3 \theta\right]\right\}} \quad\left(0^{\circ} \leq \theta \leq 60^{\circ}\right) .
$$

Finally, using Equations (4), (5), and (20), the entire strength criterion for frozen saline silty clay can be expressed as

$$
\begin{aligned}
F= & \frac{a(s)\left(p / p_{\mathrm{a}}\right)^{2}+b(s)\left(p / p_{\mathrm{a}}\right)+c(s)}{\left(p / 9.8687 p_{\mathrm{a}}\right)+d(s)} p_{\mathrm{a}} \\
& \times\left[\frac{\sqrt{3}\left(\sqrt{8+\sin ^{2} \varphi_{0}}-\sin \varphi_{0}\right)}{4 \sqrt{2+\sin ^{2} \varphi_{0}} \cos \vartheta}\right]-q=0 .
\end{aligned}
$$

We take the failure curve when salt content is $1.5 \%$ as an example to study failure curves of frozen saline silty clay. The failure surface and the shape function curves of this strength criterion with salt content $1.5 \%$ are shown in Figure 6.

From Figures 6(a) and 6(b), it can be seen that the failure surface for frozen saline silty clay in principal stress space with salt content $1.5 \%$ is a curved surface, whose opening increases first and then decreases. The shape function in $\pi$ 


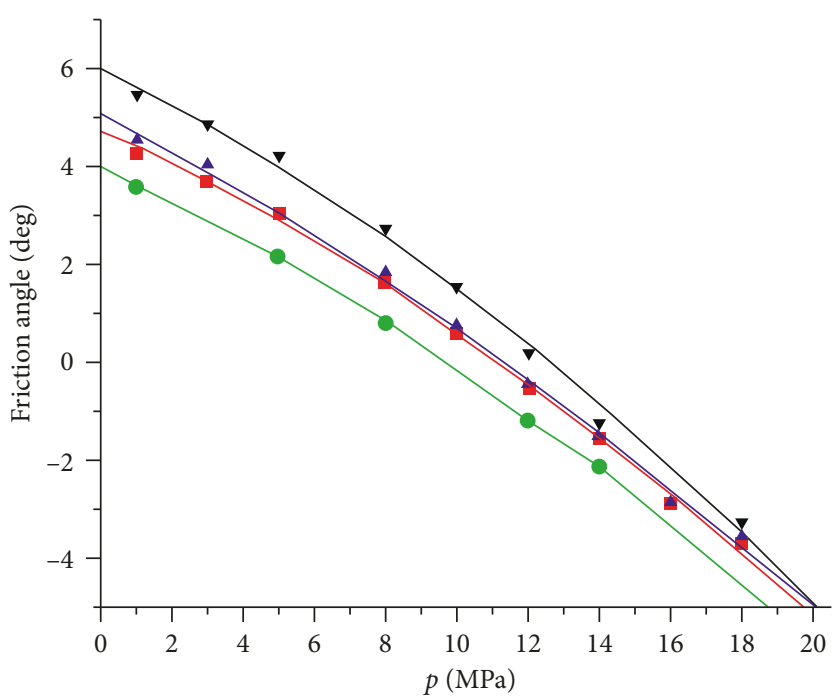
- Salt $0 \%$
- Salt $1.5 \%$
- Salt $0.5 \%$
v Salt $2.5 \%$

FIGURE 4: Relationship between hydrostatic pressure and friction angle of frozen saline silty clay with different salt contents.

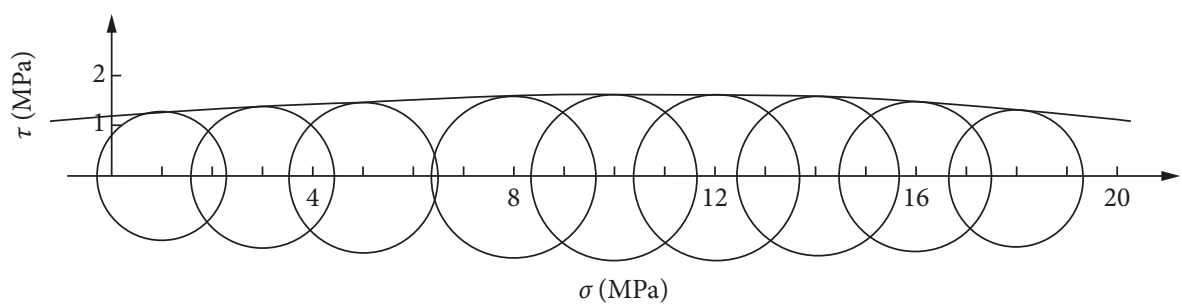

FIGURE 5: The shear strength envelope of frozen saline silty clay.

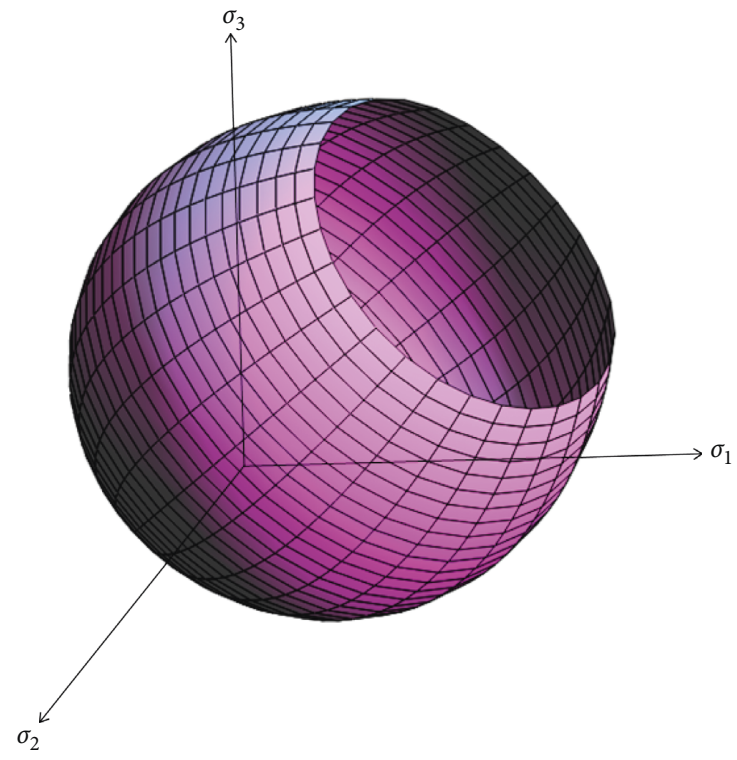

(a)

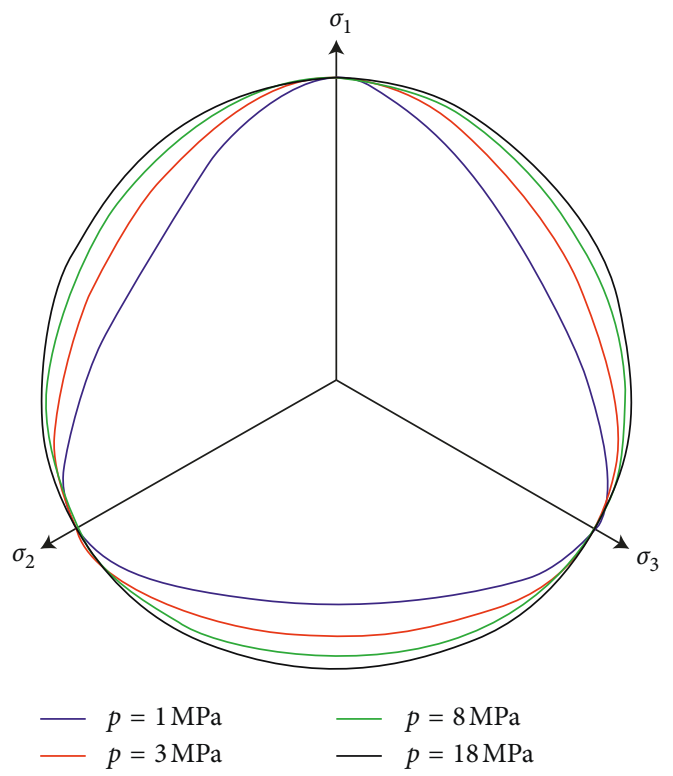

(b)

Figure 6: The failure surface and the shape function curves for frozen saline silty clay with salt content $1.5 \%$ : (a) principal stress space; (b) $\pi$ plane. 


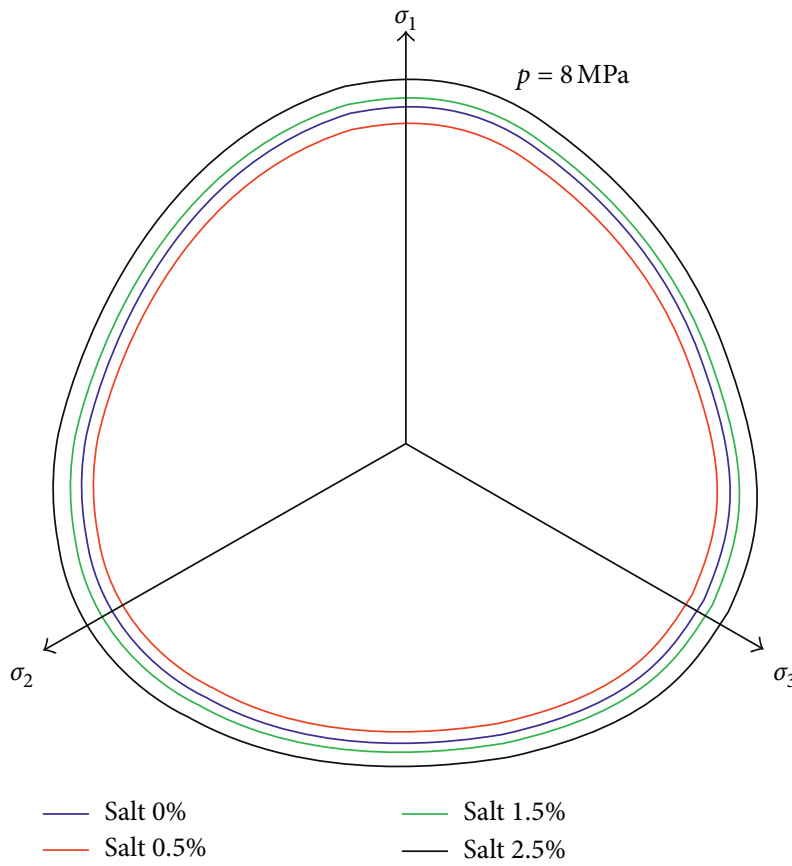

(a)

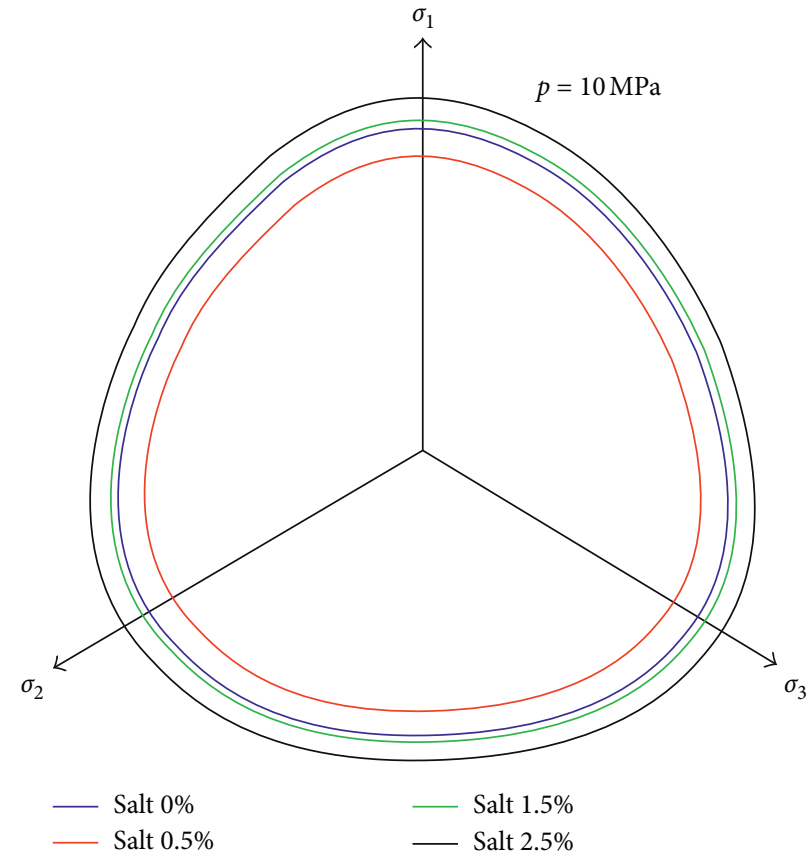

(b)

Figure 7: The shape function curves in the $\pi$ plane with different salt contents: (a) $p=8 \mathrm{MPa}$; (b) $p=10 \mathrm{MPa}$.

plane is a curved triangle when the hydrostatic pressure $p=1 \mathrm{MPa}$; with the increase of the hydrostatic pressure, the shape function changes from curved triangle to circle, and the shape function is approximately a circle when the hydrostatic pressure $p=18 \mathrm{MPa}$. The shape function curves with different salt contents in the $\pi$ plane are shown in Figure 7. From Figures 7(a) and 7(b), it can be seen that the shape function changes versus salt content variation from $0.0 \%$ to $2.5 \%$ when the hydrostatic pressure $p$ is a constant. The innermost curve is the shape function curve of frozen saline silty with salt content $0.5 \%$, while the outermost curve is the shape function curve of frozen saline silty with salt content $2.5 \%$. Therefore, the strength reached a minimum value when salt content is equal to $0.5 \%$, while it reached a maximum value when salt content is equal to $2.5 \%$.

\section{Conclusions}

A series of conventional triaxial compression tests were carried out for frozen saline silty with $\mathrm{Na}_{2} \mathrm{SO}_{4}$ contents 0.0 , $0.5,1.5$, and $2.5 \%$ under confining pressures ranging from $0 \mathrm{MPa}$ to $18 \mathrm{MPa}$ at $-6^{\circ} \mathrm{C}$, respectively. From the test results, the following conclusions can be made:

(1) The strength of frozen saline silty clay presents obvious nonlinearity under each salt content, and the strength of frozen saline silty clay increases with increasing confining pressures under low confining pressures, but the strength decreases with a further increase in confining pressures.

(2) The salt contents have an important influence on strength of frozen saline silty clay. The strength reaches a minimum value when salt content is equal to $0.5 \%$, while it reaches a maximum value when salt content is equal to $2.5 \%$.

(3) The slope $k$ of the CSL of frozen saline silty clay under different salt contents is different when the hydrostatic pressure $p<8 \mathrm{MPa}$. In this study, it is $k_{0.5}<k_{0}<k_{1.5}<k_{2.5}$.

(4) The strength criterion proposed in this paper could well reflect the effects of confining pressures and salt contents on strength properties of frozen saline silty clay. The shape function in the $\pi$ plane changes from curved triangle to circle with the increases of the hydrostatic pressure.

\section{Data Availability}

The data used to support the findings of this study are included within the article.

\section{Conflicts of Interest}

The authors declare that they have no conflicts of interest.

\section{Acknowledgments}

This research was supported by the National Key Research and Development Program of China (Grant No. 2018YFC0809605), Key Research Program of Frontier Sciences of Chinese Academy of Sciences (Grant No. QYZDYSSW-DQC015), National Key Basic Research Program of China (973 Program No. 2012CB026102), National Natural Science Foundation of China (Grant Nos. 41230630 and 41701068), and Program of the State Key Laboratory of Frozen Soil Engineering (Grant No. SKLFSE-ZT-23). 


\section{References}

[1] X. Z. Xu, J. C. Wang, L. X. Zhang, and Z. X. Tao, Mechanisms of Frost Heave and Soil Expansion of Soils, Science Press, Beijing, China, 1995.

[2] H. Matsuoka and T. Nakai, "Stress-deformation and strength characteristics of soil under three different principal stresses," Proceedings of the Japanese Society of Civil Engineers, vol. 1974, no. 232, pp. 59-70, 1974.

[3] P. V. Lade and J. M. Duncan, "Elasto-plastic stress-strain theory for cohesionless soil," Journal of the Geotechnical Engineering Division, vol. 101, no. 10, pp. 1037-1053, 1975.

[4] A. Gajo and D. Muir Wood, "A kinematic hardening constitutive model for sands: the multiaxial formulation," International Journal Numerical and Analytical Methods in Geomechanics, vol. 23, no. 9, pp. 925-965, 1999.

[5] J. M. Pestana, A. J. Whittle, and L. A. Salvati, "Evaluation of a constitutive model for clays and sands: Part I-sand behavior," International Journal Numerical and Analytical Methods in Geomechanics, vol. 26, no. 11, pp. 1097-1121, 2002.

[6] Y. P. Yao, W. Hou, and A. N. Zhou, "UH model: threedimensional unified hardening model for overconsolidated clays," Geotechnique, vol. 59, no. 5, pp. 451-469, 2009.

[7] N. A. Tsytovich, The Mechanics of Frozen Ground, Science Press, Beijing, China, 1985.

[8] O. B. Andersland and I. Ainouri, "Time-dependent strength behavior of frozen soils," Journal of the Soil Mechanics and Foundation Division, vol. 96, no. 4, pp. 1249-1265, 1970.

[9] B. D. Alkire and O. B. Andersland, "The effect of confining pressure on the mechanical properties of sand-ice materials," Journal of Glaciology, vol. 12, no. 66, pp. 469-481, 1973.

[10] F. D. Haynes and J. A. Karalius, Effect of Temperature on the Strength of Frozen Silt, Cold Regions Research and Engineering Laboratory, Hanover, NH, USA, 1977.

[11] S. S. Vialov, Determination of Strength and Creep for Artificially Frozen Soils, Stroyizdat, Leningr.otdelenie, Leningrad, Russia, 1981.

[12] V. R. Parameswaran and S. J. Jones, "Triaxial testing of frozen sand," Journal of Glaciology, vol. 27, no. 95, pp. 147-155, 1981.

[13] T. H. W. Baker, S. J. Jones, and V. R. Parameswaran, "Confined and unconfined compression tests of frozen sand," in Proceedings of 4th Canadian Permafrost Conference National Research Council of Canada, pp. 387-392, Canada, 1982.

[14] J. M. Ting, R. T. Martin, and C. C. Ladd, "Mechanisms of strength for frozen sand," Journal of Geotechnical Engineering, vol. 109, no. 10, pp. 1286-1302, 1983.

[15] Y. L. Zhu and D. L. Carbee, "Uniaxial compressive strength of frozen silt under constant deformation rates," Cold Regions Science and Technology, vol. 9, no. 1, pp. 3-5, 1987.

[16] Y. L. Zhu and D. L. Carbee, Creep and Strength Behaviour of Frozen Silt in Uniaxial Compression, Cold Regions Research and Engineering Laboratory, Hanover, NH, USA, 1987.

[17] I. E. Guryanov and W. Ma, "Strength characteristics of frozen soil under loading and unloading," Journal of Glaciology and Geocryology, vol. 18, no. 1, pp. 53-57, 1995, in Chinese.

[18] W. Ma, Z. W. Wu, L. X. Zhang, and X. X. Chang, "Analyses of process on the strength decrease in frozen soils under high confining pressure," Cold Regions Science and Technology, vol. 29, no. 1, pp. 1-7, 1999.

[19] W. Ma and X. X. Chang, "Analyses of strength and deformation of an artificially frozen soil wall in underground engineering," Cold Regions Science and Technology, vol. 34, no. 1, pp. 11-17, 2002.
[20] D. Y. Wang, W. Ma, X. X. Chang, and A. G. Wang, "Study on the resistance to deformation of artificially frozen soil in deep alluvium," Cold Regions Science and Technology, vol. 42, no. 3, pp. 194-200, 2005.

[21] Y. M. Lai, H. B. Cheng, Z. H. Gao, and X. X. Chang, "Stress-strain relationships and nonlinear Mohr strength criterion of frozen sand clay," Chinese Journal of Rock Mechanics and Engineering, vol. 26, no. 8, pp. 1612-1617, 2007.

[22] Y. M. Lai, L. Jin, and X. X. Chang, "Yield criterion and elastoplastic damage constitutive model for frozen sandy soil," International Journal of Plasticity, vol. 25, no. 6, pp. 11771205, 2009.

[23] Y. M. Lai, Y. G. Yang, X. X. Chang, and S. Y. Li, "Strength criterion and elastoplastic constitutive model of frozen silt in generalized plastic mechanics," International Journal of Plasticity, vol. 26, no. 10, pp. 1461-1484, 2010.

[24] E. Chamberlain, C. Groves, and R. Perham, "The mechanical behaviour of frozen earth materials under high pressure triaxial test conditions," Géotechnique, vol. 22, no. 3, pp. 469-483, 1972.

[25] J. L. Qi and W. Ma, "A new criterion for strength of frozen sand under quick triaxial compression considering effect of confining pressure," Acta Geotechnica, vol. 2, no. 3, pp. 221226, 2007.

[26] A. M. Fish, "Strength of frozen soil under a combined stress state," in Proceedings of 6th International Symposium on Ground Freezing, vol. 1, pp. 135-145, A.A. Balkema, Beijing, China, September 1991.

[27] W. Ma, Z. Wu, and X. X. Chang, "Effect of confining pressure on strength behaviour of frozen soil," Chinese Journal of Geotechnical Engineering, vol. 17, no. 5, pp. 7-11, 1995.

[28] Y. G. Yang, Y. M. Lai, and J. B. Li, "Laboratory investigation on the strength characteristic of frozen sand considering effect of confining pressure," Cold Regions Science and Technology, vol. 60, no. 3, pp. 245-250, 2010.

[29] Y. G. Yang, Y. M. Lai, Y. H. Dong, and S. Y. Li, "The strength criterion and elastoplastic constitutive model of frozen soil under high confining pressures," Cold Regions Science and Technology, vol. 60, no. 2, pp. 154-160, 2010.

[30] Y. G. Yang, F. Gao, and Y. M. Lai, "Modified Hoek-Brown criterion for nonlinear strength of frozen soil," Cold Regions Science and Technology, vol. 86, pp. 98-103, 2013.

[31] M. K. Liao, Y. M. Lai, and C. Wang, "A strength criterion for frozen sodium sulfate saline soil," Canadian Geotechnical Journal, vol. 53, no. 7, pp. 1176-1185, 2016.

[32] X. S. Wan, Laboratory investigation on salt crystals precipitation of sulfate saline soil and salt transfer and saltheaving mitigation of embankment in cold regions, Ph.D. thesis, University of Chinese Academy of Sciences, Huairou, China, 2015.

[33] People's Republic of China National Standard GB/T 501231999, Standard for Soil Test Method, China Planning Press, Beijing, China, 1999.

[34] J. Chu, "An experimental examination of the critical state and other similar concepts for granular soils," Canadian Geotechnical Journal, vol. 32, no. 6, pp. 1065-1075, 1995.

[35] Y. P. Yao, J. Hu, A. N. Zhou, T. Luo, and N. D. Wang, "Unified strength criterion for soils, gravels, rocks, and concretes," Acta Geotechnica, vol. 10, no. 6, pp. 749-759, 2015.

[36] H. Matsuoka, Y. P. Yao, and D. Sun, "The cam-clay models revised by the SMP criterion," Soils and Foundations, vol. 39, no. 1, pp. 81-95, 1999. 


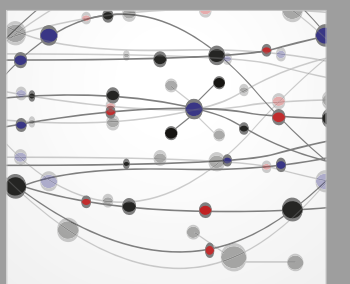

The Scientific World Journal
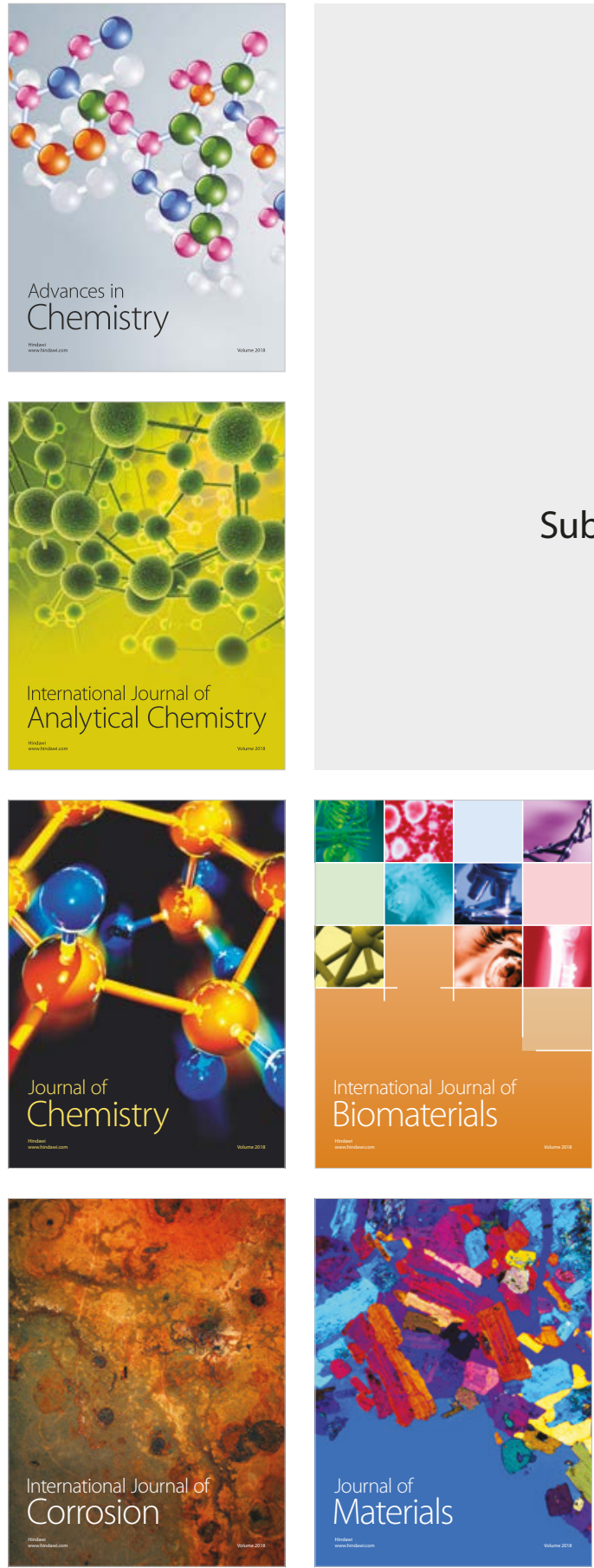

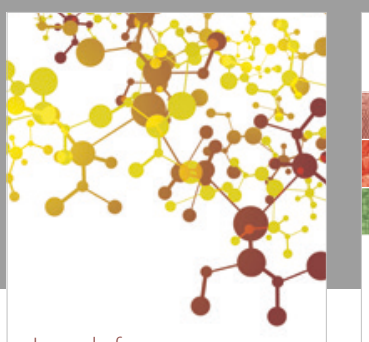

Journal of

Applied Chemistry
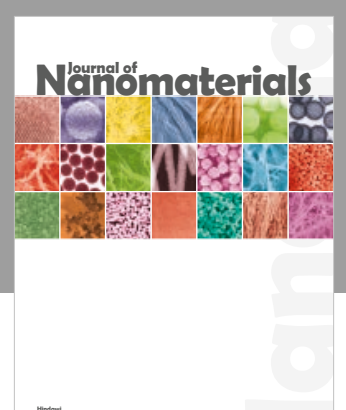

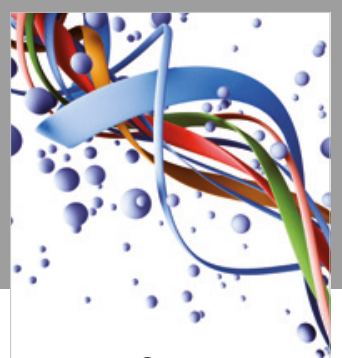

Scientifica

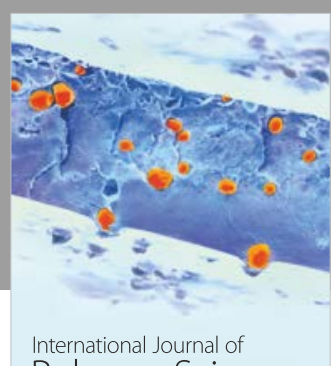

Polymer Science

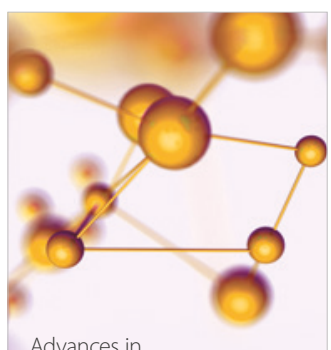

Physical Chemistry
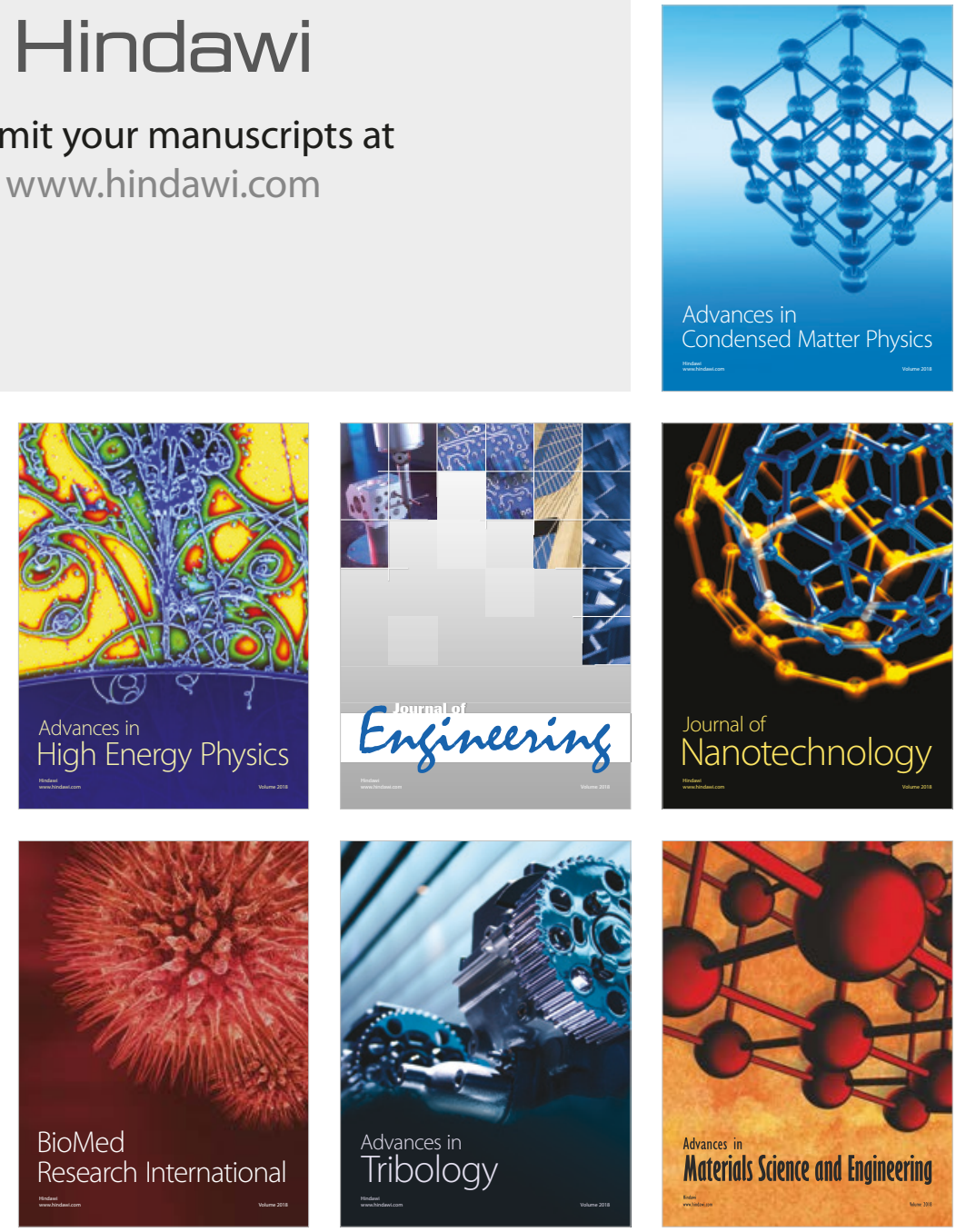